\title{
Decolonizing Knowledge Organization Systems: Hawaiian Epistemology, Representation and Organization
}

\author{
Shavonn-Haevyn Matsuda \\ University of Hawai'i Maui College \\ shavonn@hawaii.edu
}

\author{
Luz Marina Quiroga, Ph.D. \\ Information and Computer Science \\ \& Library and Information Science \\ University of Hawai'i at Mānoa \\ lquiroga@hawaii.edu
}

\author{
Lala Hajibayova, Ph.D. \\ School of Information \\ Kent State University \\ lhajibay@kent.edu
}

\author{
Keahiahi Long \\ Hawai'inuiākea School of \\ Hawaiian Knowledge \\ University of Hawai'i at Mānoa \\ keahiahi@hawaii.edu
}

\author{
Wayne Buente, Ph.D. \\ School of Communications \\ University of Hawai'i at Mānoa \\ wbuente@hawaii.edu
}

\begin{abstract}
Through examining controlled and natural language representation of Hawai' $i$, this research aims to contribute to an understanding of how Hawaiian epistemology may enrich Hawaiian cultural heritage representation in conventional knowledge organization systems.
\end{abstract}

\section{Keywords}

Hawaiian epistemology, knowledge organization systems, Indigenous knowledge, Dewey Decimal Classification, anticolonial strategies, indigenous ontologies.

\section{INTRODUCTION}

Current systems are largely insufficient for describing and organizing indigenous knowledge and can also be distressing for indigenous researchers and communities. In a series of studies, Olson (e.g., 1998, 2001, 2007), has demonstrated that by favoring a mainstream view, controlled vocabularies often introduce "blatant biases or, more commonly, subtle, insidious marginalization" (Olson, 2002, p. 6). Olson's (2002) analysis of the Dewey Decimal Classification and Library of Congress Subject Headings representations of 11 books related to African American women, Chicanas, lesbians, Asian American women, working class women, Jewish women, and North American Aboriginal women demonstrates that subject representation of the analyzed books is excluded from the "mainstream and then pushed aside where it will not disturb library users looking for books on real topics" (p. 223, emphasis in the original). Doyle (2006) has shown that indigenous peoples in the United States have been marginalized in universal

Advances in Classification Research, 2017, October 27, 2017, Washington, DC, USA. knowledge organization systems "through historicization, omission, lack of specificity, lack of relevance and lack of recognition of sovereign nations" (p. 437). Artifacts represent indigenous knowledge only when they are placed in context within their worlds of meaning. Moreover, documents or other resources are not treated as containing static and "frozen" or preserved knowledge, as in so many museums, archives, and libraries, but rather with the aim of transmitting dynamic knowledge for future generations (Grenersen, 2012). These ways of knowing, they emphasize, are not text-based but rather "oral, communal, aesthetic, kinesthetic, and emergent from living landscapes" (Duarte and Belarde-Lewis, 2015, p. 685). As a result, indigenous peoples have had to accept their effective marginalization by using inaccurate and imprecise organization of documents and subject headings or through collecting their own items in "smaller, flexible, sometimes ephemeral, private offline and online locations" (Duarte and Belarde-Lewis, 2015, p. 679).

Meyer (2008) contends that Hawaiian epistemology locates meaning at the triangulation of body, mind, and spirit. Meyer (2001) also identified the following seven pillars of Hawaiian epistemology: spirituality and knowing (i.e., the cultural context of knowledge), that which feeds (i.e., physical place and knowing), the cultural nature of the senses (i.e., expanding the idea of empiricism), relationship and knowledge (i.e., self through other), utility of knowledge (i.e., ideas of wealth and usefulness), words and knowledge (i.e., causality in language and thought), and the body-mind question (i.e., illusions of separation) ( p. 126). 
According to Meyer, "meaningful research asks us to project beyond our objective/empirical knowing (body) into wider spaces of reflection offered through conscious subjectivity (mind) and, finally, via recognition and engagement with deeper realities (spirit)" (2008, p. 224). Based on this conceptualization of indigenous methodology as relational accountability or being accountable to all relations, indigenous knowledge representation should be answerable to such questions as: Do representations of the resources fulfill all potential relationships with the world?

Preliminary analysis of Dewey Decimal Classification (DDC) system demonstrated the lack of comprehensive representation of Hawaiian culture. For example, the search in WebDewey using the terms "Hawaii" to find what relevant class numbers are available in the DDC, returns options to classify Hawaiian Islands through relative indexes:

T2--969 - Hawaii and neighboring north central Pacific Ocean islands; T2--9691-T2--9694 - Hawaii; T2--9691Hawaii County (Hawaii Island); T2--9692- Maui County; T2--96921 - Maui Island; T2--96922 - Kahoolawe Island; T2--96923 - Lanai Island; T2--96924 - Molokai Island; T2-9693 - Honolulu County (Oahu Island); T2--96931 Honolulu; T2--9694 - Kauai County; T2--96941- Kauai Island; T2--96942- Niihau Island; T5--050901-T5--050909Europeans and people of European descent of mixed ancestry with specific non-European ethnic and national groups; T5--9942- Hawaiians (Native people).

The DDC relative indexes also provide terms to build classes for representation of Hawaiians as an ethnic group:

T5--0 - Table 5. Ethnic and National Groups; T5--1-T5--9 Specific ethnic and national groups; T5--9 - Other ethnic and national groups; T5--99 - Papuans; Aboriginal Australians and Tasmanians; Malayo-Polynesian and related peoples; miscellaneous peoples; T5--99/4 - Peoples who speak, or whose ancestors spoke, Polynesian languages; T5--99/42 - Hawaiians (Native people), . . .

A DDC note leads to the 068.969 class number for representing general organizations in Hawaii. And the note for representation of journalism and newspapers in Hawaii falls under the class number 079.969.

DDC also provides class numbers for representing political parties in Hawaii:
324.24-324.29

324.2969

$234.2969 / 01-324.2969 / 08$

DDC also includes a note for Hawaiian cooking (641.59969 - Cooking - Hawaii).

600

640

641

641.5

641.59

641.593-641.599

641.59969

Social sciences

Political science

The political process

Political parties

Parties in specific countries and localities in modern world

Parties in Hawaii

Parties in Hawaii

Technology

Home \& family management

Food and drink

Cooking

Cooking characteristic of specific geographic environments, ethnic cooking

Cooking characteristic of specific continents, countries, localities

Cooking--Hawaii

DDC notes also suggest the class numbers 347.969 to classify civil procedures and courts of Hawaii; 348.969 for laws, regulations, court cases of Hawaii; 647.95969 for restaurants in Hawaii; and 708.996 for galleries, museums, and private collections in Hawaii.

Even though DDC provides some flexibility to generate class numbers, representation of indigenous knowledge requires a deep understanding of indigenous worldview. For instance, previous analysis of DDC class numbers generated to represent Hawaiian Hula has demonstrated lack of understanding of Hawaiian Hula as creative art 
form, and misrepresenting it as recreational activity and folk dance (Hajibayova \& Buente, 2017).

Simpson (2004) offers some anticolonial strategies for how to ensure the survival of indigenous knowledge and, thus, indigenous peoples through the dismantling of colonial structures like conventional library and information science systems. Simpson (2004) argues that those of privilege (e.g. settler governments, Western academics) must take an active role alongside indigenous knowledge communities to deconstruct the relationship between colonial thinking and indigenous knowledge, recover indigenous intellectual traditions, and create spaces for indigenous knowledge systems and their inherent processes, values, and traditions.

Matsuda (2015) proposes addressing the inadequacies of such conventional library and information science systems through the creation of a Hawaiian knowledge organization system. Key considerations include the immensity of Hawaiian knowledge, complexities of using the Hawaiian language within such a system, and the importance of collaboration in its creation and maintenance. Additionally, inclusion of the Hawaiian community at each stage of development is crucial to the integrity of any proposed system if the purpose is to improve representation, organization, and access to Hawaiian collections and communities.

As the foundation for a Hawaiian knowledge organization system continues to be established, this research into Hawaiian epistemology and processes of decolonization will better inform current practices related to classification and representation of Hawaiian knowledge in conventional library and information science systems.

\section{REFERENCES}

Duarte, M.E., \& Belarde-Lewis, M. (2015). Imagining: Creating spaces for indigenous ontologies." Cataloging \& Classification Quarterly 53(5-6), 677702.

Doyle, A. M. (2006). Naming and reclaiming indigenous knowledge: Intersections of landscape and experience. In G. Budin, C. Swertz \& K.
Mitgutsch (Eds.), Advances in knowledge organization (10), Knowledge Organization for a Global Learning Society: Proceedings of the Ninth International ISKO Conference in Vienna, Austria, 2006, (pp. 435-442). Würzburg: Ergon Verlag.

Grenersen, G. (2012). "What is a document institution? A case study from the South Sámi community." Journal of Documentation 68(1), 127-133.

Hajibayova, L., \& Buente, W. (2017). Representation of Indigenous cultures: Considering the Hawaiian Hula. Journal of Documentation 73(6), 1137-1148.

Matsuda, S. (2015). Toward a Hawaiian Knowledge Organization System: A Survey on Access to Hawaiian Knowledge in Libraries and Archives (master's thesis). University of Hawai'i at Mānoa, Honolulu, HI.

Meyer, M.A. (2001). "Our Own Liberation: Reflections on Hawaiian Epistemology." The Contemporary Pacific 13(1), 124-148.

Meyer, M. A. (2008). Indigenous and authentic: Hawaiian epistemology and the triangulation of meaning. In N. K. Denzin, Y. S. Lincoln, \& L. T. Smith (Eds.), Handbook of critical and indigenous methodologies (pp. 217-232). Los Angeles: Sage.

Olson, H. A. (1998). “Mapping beyond Dewey's boundaries: Constructing classificatory space for marginalized knowledge domains." Library Trends 47(2), 233-254.

Olson, H. A. (2000). "Difference, culture and change: The untapped potential of LCSH." Cataloging \& Classification Quarterly 29(1-2), 53-71.

Olson, H. A. (2001). "Sameness and difference: A cultural foundation of classification." Library Resources \& Technical Services 45(3), 115-122.

Olson, H. A. (2002). The Power to Name: Locating the Limits of Subject Representation in Libraries. Dordrecht, Netherlands: Kluwer Academic Publishers.

Simpson, L. R. (2004). "Anticolonial strategies for the recovery and maintenance of indigenous knowledge." The American Indian Quarterly 28(3), 373-338. 